\title{
Comparando interesses: considerações sobre o "problema" que Arneson imputa a Singer
}

\author{
Anselmo Carvalho de Oliveira*
}

\begin{abstract}
Resumo: Richard Arneson identifica um "problema" no Princípio de Igual Consideração de Interesses (PICI) proposto por Peter Singer: não seria suficiente para garantir a igualdade entre todos os seres humanos e, ao mesmo tempo, garantir a superioridade em relação aos animais nãohumanos. O PICI reintroduziria a hierarquia do valor moral entre os seres humanos fundamentada na diferença das capacidades mentais apresentadas por cada individuo. Neste artigo, argumento que o "problema" identificado por Arneson é decorrente dos pressupostos intuitivos que assume, portanto, não é um problema de coerência interna da filosofia moral de Singer.

Palavras-chave: Peter Singer; Richard Arneson; Princípio de Igual Consideração de Interesses; Animais não-humanos; Seres humanos.

Abstract: Richard Arneson identified a "problem" in the Peter Singer's Principle of Equal Consideration of Interests (PECI): not be sufficient to ensure the equality of all human beings and at the same time ensuring superiority over non-human animals. The PECI would lead to moral value hierarchy among humans based on differences in mental capacities made by each individual. In this article, I argue that the "problem" identified by Arneson is due to the assumptions intuitive assumes, therefore, is not a problem of internal consistency of Peter Singer's moral philosophy.

Keywords: Richard Arneson; Peter Singer's Principle of Equal Consideration of Interests; non-human animals; Humans.
\end{abstract}

recebido: $02 / 2014$

aprovado: $07 / 2014$

\section{Argumento Contra o Especismo}

Peter Singer propõe o princípio de igual consideração de interesses (PICI) como um princípio substancial capaz de

* Bacharel em Filosofia (UFSJ), Especialista em Bioética (UFLA), mestre em Filosofia(UFRN).Em@il: anselmocarvalhooliveira@yahoo.com.br

Problemata: R. Intern. Fil. v. 5. n. 1 (2014), p. 28-42 ISSN 2236-8612 doi:http://dx.doi.org/10.7443/problemata.v5i1.18216 
resolver problemas práticos. O PICI impõe que os interesses de cada um dos afetados devem ser pesados imparcialmente. "Força" ou "peso" é a importância que determinado interesse tem para o indivíduo que o vivência. Um interesse "mais forte" ou vários interesses que combinados "excedem em peso" um ou mais interesses devem ser favorecidos. Em situações de conflito, os interesses que são menos pesados não podem ter prioridade em relação aos que são mais pesados. O interesse básico é evitar o sofrimento. Básico porque é vivenciado por todos os seres sencientes independentemente se são autoconscientes, racionais ou tenham preferências no futuro ${ }^{1}$.

A capacidade de sentir, senciência, é condição suficiente e necessária para que um indivíduo pertença à comunidade moral. Suficiente porque independente de qualquer outra característica (seja a espécie, a raça, o sexo, a inteligência etc.), habilita um indivíduo a ser membro da comunidade moral. E necessária porque todos os seres que não a possuem são excluídos da comunidade moral (como, por exemplo, plantas, rios ou cadeias de montanhas etc.).

O PICI assevera a abordagem consequencialista na ética: um agente deve fazer aquilo que levará, de acordo com os conhecimentos disponíveis sobre as circunstâncias, aos melhores resultados. Tudo o mais sendo igual, as melhores consequências são determinadas segundo o maior bem-estar que traz para cada um dos afetados. O bem-estar é considerado imparcialmente: o bem-estar de cada indivíduo é tão importante quanto o bem-estar de qualquer outro.

O PICI é um princípio de igualdade que rejeita tipos de discriminação como o racismo, o sexismo e o especismo. No especismo, os interesses dos indivíduos da própria espécie - no caso, os Homo Sapiens -, são considerados intrinsecamente mais valiosos em relação aos interesses com o mesmo peso de indivíduos das outras espécies. A espécie é determinada de acordo com as suas características biológicas e genéticas que, em geral, são manifestadas em diferenças na aparência. $O$ especismo parte do mesmo princípio que o racismo. Segundo Singer (2006, p. 68),

Os racistas violam o princípio de igualdade ao darem maior importância aos interesses dos membros de sua raça sempre que se verifica um choque entre os seus 
interesses e os interesses dos que pertencem a outra raça. Sintomaticamente, os racistas de descendência europeia não admitiram que, por exemplo, a dor importa tanto quando é sentida por africanos como quando é sentida por europeus. Da mesma forma, aqueles que eu chamaria de "especistas" atribuem maior peso aos interesses de membros de sua própria espécie quando há um choque entre os seus interesses e os interesses dos que pertencem a outras espécies. Os especistas humanos não admitem que a dor é tão má quando sentida por porcos ou ratos como quando são os seres humanos que a sentem.

Singer rejeita que a igualdade dependa da pose de características determinadas pela constituição biológica de uma espécie: "os fatos biológicos que determinam a linha divisória de nossa espécie não têm um significado moral" (SINGER, 2006, p. 98). Pertencer a uma espécie não é suficiente ou necessário para justificar uma consideração desigual para com os seres de outras espécies. Se encontrássemos um alienígena sob a forma de muco verde, mas parecido com os seres humanos em aspectos moralmente relevantes, a saber, se tiver interesses, não seria justificado deixar de considerá-lo como membro da comunidade moral pela simples razão de que ele não é um ser humano (cf. SINGER, 2006, p. 66ss e 98ss; ARNESON, 1999, p. 103).

Uma defesa mais refinada da igualdade, que justifique a prioridade dos seres humanos em relação aos animais nãohumanos, poderia ser baseada na identificação de alguma "característica X" moralmente relevante que tão somente os seres humanos possuem. A "característica X" poderia ser a posse da "personalidade moral", isto é, a propriedade que os seres humanos têm de "fazer uma invocação moral com alguma perspectiva de que a invocação vai ser levada em consideração" (SINGER, 2006, p. 27). Poderia ser a capacidade de autonomia, de racionalidade, de linguagem, de usar ferramentas, de estabelecer acordos de responsabilidades mútuas, de compreensão recíproca sobre a respeitabilidade dos direitos do outro quanto dos seus próprios. Nessa linha de argumentação, assume-se também a posição normativa segundo a qual os indivíduos que cumprem o critério moral (a posse da "característica X") tem valor intrínseco e devem ser considerados como fins: não podem ser usados como meios para 
realizar os interesses de nenhum outro indivíduo. Seres que não possuem a "característica $X$ " não tem valor intrínseco, tão somente valor instrumental, indireto e condicionado por uma vontade extrínseca a sua: eles podem ser usados como meios para realizarem outros interesses que não os seus. Se existe algum intuito de protegê-los, esse depende dos benefícios que possam trazer para os seres que possuem a "característica X".

Entretanto, parece ser sensivelmente falso que todos os seres humanos tenham qualquer característica que possa ser escolhida como uma "característica X" moralmente relevante. Tampouco é verdade que os seres humanos que tenham determinada "característica X" moralmente relevante, qualquer que possa ser, tenham-na igualmente. É facilmente verificado empiricamente que qualquer "característica $X$ " relevante varie em grau dependendo de quem é o indivíduo particular considerado (cf. SINGER, 2010, p. 6; SINGER, 2003c, p. 120121). De fato, cada indivíduo apresenta diferentes capacidades morais, intelectuais, de experimentar o prazer e a dor, de comunicação, intensidade diferente dos seus sentimentos morais, de sensibilidade em relação aos outros etc.

O problema é que se existe uma variação de grau, seria preciso definir qual é o grau mínimo para que um indivíduo possa ser considerado membro da comunidade moral. Uma "característica X" que fosse ampla o suficiente para abranger todos os seres humanos precisaria apresentar um grau tão baixo que qualquer que fosse ela alguns animais não-humanos também a possuiria. Se, por exemplo, a "característica $X$ " moralmente relevante for a racionalidade ou a linguagem, alguns animais possuem essas características em graus mais altos do que muitos seres humanos, por exemplo, alguns grandes símios são capazes de aprenderem a linguagem de sinais (cf. WHITEN; SCHAIK, 2007, p. 613-615; TELES, 2005, p. 167). Bentham fez notar: "o que mais deveria traçar a linha insuperável? A faculdade da razão, ou, talvez, a capacidade de falar? Mas, para lá de toda a comparação possível, um cavalo ou um cão adulto são mais sociáveis, do que um bebê de um dia, uma semana, ou até mesmo um mês" (BENTHAM, 1979, p. 63; cf. SINGER, 2006, p. 66-67).

Sendo assim, ou alguns animais devem ser tratados com a mesma consideração que os seres humanos; ou alguns seres 
humanos ficariam abaixo da linha de consideração moral, pois possuem a "característica $X$ " relevante em um grau tão baixo que o seu status moral seria o mesmo dos animais não-humanos, que ordinariamente são considerados objetos.

[...] lembremo-nos de que existem seres humanos com deficiências mentais que podemos considerar menos autoconscientes ou autônomos do que muitos animais. Se usarmos essas características para colocar um abismo entre os seres humanos e outros animais, estaremos colocando esses seres humanos menos capazes do outro lado do abismo; e, se o abismo for usado para marcar uma diferença de status moral, então esses seres humanos teriam o status moral de animais, e não de seres humanos. (SINGER, 2006, p 85).

Justificar a superioridade dos seres humanos sobre os seres não-humanos a partir da posse de uma "característica $X$ " relacionada com as capacidades mentais que variam em grau em relação a cada indivíduo particular coloca em bancarrota a ideia de um princípio de igualdade válido indistintamente para todos os seres humanos. Entretanto, aqueles que defendem a igualdade fundada na pose das capacidades intelectuais têm como um de seus objetivos assegurar um igualitarismo com sentido moral para todos os seres humanos sem distinções de grau. Assim, se a fundamentação da dignidade dos seres humanos se deduz das suas capacidades mentais superiores ${ }^{2}$, o argumento não se sustenta.

\section{O Problema Que Arneson Imputa a Singer}

Richard Arneson, no artigo What, If Anything, Renders All Humans Morally Equal? (1999), faz uma análise das implicações do PICI e as suas consequências para o alcance prático da igualdade.

Para Arneson, se existem diferenças de grau na capacidade mental dos seres humanos e se essas diferenças de grau são moralmente relevantes, consequentemente, criar-se-á uma hierarquia entre os seres humanos baseada no grau que eles possuem dessas capacidades. Um princípio de igualdade que justifica a hierarquia das capacidades entre os seres humanos 
não é aceito por Arneson, na medida em que não coincidiria com o pressuposto fundamental que assume: "a igual consideração de todos os seres humanos" (ARNESON, 1999, p. 106). Para Arneson (1999, p. 104), “o argumento de diferentes capacidades intelectuais que pretende justificar a desigualdade moral fundamental das espécies animais também justificaria a negação da igualdade moral fundamental entre todos os seres humanos".

Singer procura resolver esse problema ao propor o PICI como o princípio moral básico. Ao assumir o PICI, a "característica X" moralmente relevante passa a ser a senciência. É nesse sentido que Singer pode afirmar que "todos os animais [sencientes] são iguais". Entretanto, a igualdade para todos os animais levaria, segundo Arneson, a uma consequência fortemente contra-intuitiva: se uma dor sentida por um animal não-humano for mais forte do que uma dor sentida por um ser humano, ela deve contar com o mesmo peso ou com peso maior. Se fosse preciso escolher entre causar/evitar uma dor de dente em um recém-nascido ou uma dor mais forte em um rato, o PICI parece exigir que a decisão correta, do ponto de vista da ética, seja a de causar/não evitar a dor no recém-nascido e não causar/evitar a dor mais forte do rato.

Essa consequência evidentemente contraria a intuição moral comum de que o alívio da dor do recém-nascido humano deveria ter sempre prioridade. Arneson não concorda com a posição contra-intuitiva assumida por Singer, que os interesses dos seres humanos e dos animais devam ser considerados de um ponto de vista austeramente imparcial. Para Arneson, o PICI não consegue especificar adequadamente o estatuto da igualdade, porque não é capaz de atribuir um status moral fundamental superior para os seres humanos sobre os outros animais em razão das capacidades mentais superiores que os humanos possuem, e, ao mesmo tempo, atribuir um status moral fundamental de igualdade entre todos os seres humanos independente das diferenças nas capacidades mentais que possuem de fato.

O que eu chamo do "problema de Singer" surge se aceitarmos que as capacidades cognitivas moralmente significativas que são relevantes para a determinação do estatuto moral fundamental de um ser variam de 
indivíduo para indivíduo em grau. O problema é especificar um princípio moral para determinar o status moral fundamental e atribuir um status superior aos seres humanos em relação aos outros animais em função das capacidades cognitivas superiores dos seres humanos, mas também atribuir a todos os seres humanos um status fundamental de igualdade moral, independentemente de suas diferentes capacidades cognitivas. Mais amplamente formulado, o problema é definir princípios morais que produzem implicações intuitivamente satisfatórias para o tratamento de seres humanos e outros animais dado que as capacidades cognitivas diferem entre espécies e indivíduos. (ARNESON, 1999, p. 105).

Para Singer, no entanto, o PICI não busca justificar o sentindo intuitivo de igualdade e atribuir uma consideração especial aos seres humanos enquanto membros da espécie Homo Sapiens. Segundo a lógica interna ao PICI, algumas características próprias dos indivíduos são relevantes para a forma como vivenciam os interesses. As pessoas possuem maior conhecimento sobre o que está acontecendo, maior capacidade de previsão e memória mais detalhada etc. Essas características podem fazer com que as pessoas vivenciem interesses mais complexos e ricos. Os interesses complexos e ricos seriam mais importantes para as pessoas que os vivenciam e teriam, por essa razão, uma força maior sobre alguns interesses dos outros animais.

Recorrer às capacidades mentais superiores para estabelecer diferenças moralmente relevantes entre os interesses dos seres humanos e dos animais não-humanos reintroduziria, segundo Arneson, o elitismo moral baseado em uma hierarquia de inteligência, o que acabaria demolindo as bases do estatuto moral de igualdade proposto por Singer. As capacidades mentais superiores variam em grau em relação a cada indivíduo, desse modo, os seres humanos adultos normais (as pessoas) possuem maiores capacidades mentais do que os outros animais, mas cada ser humano particular possui um grau relativo das suas capacidades mentais, alguns possuindo uma capacidade maior do que outros. Se o maior grau das capacidades mentais de um pessoa (humana) em relação aos animais ou em relação aos seres humanos que não são pessoas justifica a prioridade dos interesses da pessoa com maior capacidade. Por extensão, 
poder-se-ia afirmar que uma pessoa que possui maior capacidade mental tem prioridade de consideração também em relação às pessoas com capacidades mentais relativamente menores. Criar-se-ia, por consequência, uma hierarquia moral baseada no grau da capacidade mental que os indivíduos possuem, em outras palavras, pessoas mais inteligentes (ou, especificamente, pessoas com uma alta pontuação em testes de Q.I.) teriam prioridade na consideração dos seus interesses. Singer, portanto, não resolveria o problema da igualdade por defender um princípio que falha em seus próprios termos.

Todavia, uma das reivindicações mais insistentes nos textos de Singer é sobre a coerência do PICI e a sua força como princípio de igualdade que elimina as discriminações em relação ao sexo, à raça, à hierarquia de inteligência e à espécie. A coerência do princípio de igual consideração de interesses depende de uma resposta convincente ao problema que Arneson coloca.

\section{Comparando Interesses}

Existe um problema metodológico em estabelecer parâmetros de comparação entre os interesses de indivíduos de diferentes espécies. Singer está ciente das dificuldades em relação às comparações interindividuais de interesses. Entretanto, mesmo que a maioria das pessoas tenham interesses que os indivíduos que não são pessoas não são capazes de ter como, por exemplo, o interesse em estudar, trabalhar, fazer planos em relação ao futuro, entre inúmeros outros, ainda assim, no mínimo seria possível comparar interesses semelhantes cujo mais importante é o interesse de evitar o sofrimento.

É possível, na concepção de Singer, equiparar os interesses dos seres humanos em relação aos interesses sobretudo, o interesse básico de evitar o sofrimento -, dos animais não-humanos sencientes. E, em algumas situações, os interesses maiores dos animais não-humanos tem prioridade sobre os interesses menores dos seres humanos. Singer (2006, p. 69) deixa claro que "em algumas situações, um membro de uma espécie sofrerá mais do que um membro de outra. Neste caso, devemos ainda aplicar o princípio de igual consideração de 
interesses, mas a consequência de fazê-lo será, é claro, dar prioridade ao alívio do sofrimento maior".

Nesse sentido, uma comparação entre a dor de um rato e a dor de um recém-nascido órfão se justificaria para Singer. Por exemplo, um rato possui uma dor cuja intensidade (baseando nas suas características individuais e da espécie a qual pertence) é considerada, por qualquer critério relevante de comparação, muito forte, talvez alguém tenha amputado sem anestesia a sua pata $^{3}$. Por outro lado, um recém-nascido está sentido uma dor na barriga como, por exemplo, cólicas, mas que não seja nada grave (consideremos também as suas características individuais e da sua espécie para estabelecer a força da sua dor). É relevante notar que ratos e recém-nascidos são seres sencientes, mas, segundo Singer, não são pessoas ${ }^{4}$, ou seja, não possuem de fato as capacidades mentais superiores e o interesse em sua existência no futuro. Suponhamos também que os dois indivíduos não correm risco de morte ${ }^{5}$.

Para comparar os interesses dos afetados no exemplo, o PICI é como uma balança imparcial que pesa a força dos interesses pendendo para o lado mais pesado. Mesmo que o interesse que possa não ser atendido seja o de um ser humano, a igual consideração deve ser assegurada a todos os indivíduos que possuem interesses. O objetivo é proteger e atribuir um mínimo de consideração moral aos interesses dos animais nãohumanos, que foram sistematicamente desconsiderados pela tradição, como Singer a interpreta, desde a Grécia Antiga. O argumento pretende mostrar a incoerência da tradição que trata os animais como objetos, pois não possuem as capacidades mentais superiores. Para essa tradição, quando se está pesando os interesses dos seres humanos o critério não é mais a posse, de fato, das capacidades mentais superiores, mas simplesmente a espécie. Os seres humanos que possuem as capacidades mentais em um nível inferior ao de muitos animais não-humanos são, ainda assim, considerados dignos de maior consideração moral.

É importante ressaltar que Singer não defende um tipo de completa inversão da moralidade. Não admite que sejam infligidas dores aos seres humanos que não são pessoas como os recém-nascidos ou os indivíduos com serias deficiências nas capacidades mentais superiores, tampouco que eles sejam excluídos da comunidade moral. 
Não desejo sugerir que os deficientes mentais devam ser forçados a ingerir alimentos com corantes até que a metade deles morra [...]. Gostaria que a nossa convicção de que seria errado tratar os deficientes mentais dessa maneira fosse transferida para os animais não-humanos em níveis semelhantes de autoconsciência e com a capacidade semelhante de sofrimento. (SINGER, 2006, p. 88).

Para Singer, os seres humanos sencientes que não possuem as capacidades mentais superiores e os animais nãohumanos sencientes são membros da comunidade moral e os seus interesses devem ser considerados imparcialmente. Nas situações em que as capacidades mentais superiores forem relevantes, pois aumentam a intensidade ou duração de um sofrimento, é, também, o sofrimento mais forte que deve ser priorizado. Essa, porém, não seria uma prerrogativa apenas das pessoas humanas. Como o grau das capacidades mentais superiores pode ter influência em relação à força de um sofrimento, a vida mental dos animais também deve ser levada em consideração. Segundo Singer (2010, p. 21), frangos, suínos, esquilos entre outros também possuem uma vida mental suficientemente complexa de tal modo que os sofrimentos que experimentam não são exclusivamente a dor física, também sofrem de estresse mental e aborrecimentos. Esses sofrimentos devem ser considerados no cálculo nos casos em que a vida mental mais complexa dos animais esteja presente.

Em sua Resposta às críticas de Arneson, Singer esclarece a sua posição: a maior quantidade de interesses envolvida no cálculo, algumas vezes, pode fazer a balança pender em favor dos interesses dos seres humanos ou das pessoas (humanas ou não). Este ponto é importante:

Porque devemos levar em conta outros interesses além do interesse em não experimentar uma dor de dente: $o$ interesse da criança em ser capaz de frequentar a escola, ou os interesses dos pais em não ver a sua criança com dor. Esses outros interesses, algumas vezes, mas nem sempre, inclinarão a balança em uma direção diferente de onde ela estaria se fôssemos considerar apenas a seriedade da dor física. 6 (SINGER, 1999, p. 294-295. Grifos nossos). 
Uma criança tem o interesse em frequentar a escola somente porque ela possui capacidades mentais superiores. Os interesses dos ratos, além do interesse em evitar o sofrimento, são limitados pelas suas capacidades mentais, que são inferiores comparadas a uma criança normal. Nesse sentido, as pessoas podem ter interesses que não são vivenciados pelos seres sencientes que não são pessoas, no caso o "interesse da criança em ser capaz de frequentar a escola". Esse interesse também deve ser considerado na soma agregada. A balança poderá ser inclinada para o lado do interesse da criança, porque o peso dos seus vários interesses somados supera em peso o interesse do rato em evitar a dor.

No utilitarismo de preferências, o interesse de cada um dos afetados conta. Assim, "os interesses dos pais em não ver a sua criança com dor" também é uma razão para dar prioridade ao interesse da criança. $O$ interesse do pai conta, tudo o mais sendo igual, como um na soma agregada. Um rato, até onde se sabe, provavelmente não possui interesse semelhante por suas crias $^{7}$. O PICI, assim, tende a favorecer, no caso, a criança. Essa é uma razão indireta para dar prioridade aos interesses do ser humano, pois considera que o mais importante não é o dano direto causado, mas o dano a terceiros ${ }^{8}$.

O sofrimento de um indivíduo senciente que não é uma pessoa teria prioridade somente se possuísse uma maior força do que o sofrimento de uma pessoa e, além disso, não houvesse nenhuma outra diferença relevante entre eles. Para Singer, entretanto, a dor de uma pessoa costuma (mas nem sempre) frustrar um maior número de interesses (indireto: nas pessoas que possuem algum tipo de afeto para com ela; ou direto: uma maior gama de interesse das pessoas) do que a dor de um animal não-humano, ainda que a intensidade e a duração com que são sentidas possam ser equivalentes. Mas isso não é o mesmo que afirmar que os interesses dos seres humanos são intrinsecamente mais valiosos, porque são os seres mais valiosos, tampouco significa que em todas as circunstâncias o interesse de um ser humano ou de uma pessoa tem prioridade de consideração.

\section{Considerações Finais}

Existe um problema para equilibrar a intuição comum de que "todos os seres humanos são iguais" e o discurso filosófico 
que justificaria essa intuição. Arneson procura encontrar justificativas filosóficas que sejam capazes de sustentar duas posições assumidas intuitivamente e que são os pressupostos para a sua discussão: 1) que todos os seres humanos têm prioridade sobre os animais, porque possuem capacidades mentais superiores; 2) que todos os seres humanos são iguais independente da variação nas capacidades mentais superiores que possa ser apresentada por cada ser humano particular.

Por que as capacidades superiores são uma justificativa para atribuir uma diferença entre espécies, mas é desconsiderada quando o problema é a igualdade entre os membros da espécie Homo Sapiens? Essa é uma questão que Arneson tem que responder satisfatoriamente se quiser justificar esse ponto sem cair no especismo, mas ele mesmo admite não ter uma resposta satisfatória: "minha busca por uma resolução do problema de Singer tem levado a resultados decepcionantes." (ARNESON, 1999, p. 123). Singer não tem a intenção de justificar a concepção intuitiva que é o pressuposto de Arneson. $\mathrm{Na}$ concepção de Singer, uma teoria moral não tem como sua função defender as concepções morais ordinárias, mas questioná-las em seus próprios fundamentos para verificar se são ou não justificadas racionalmente. O princípio de igual consideração de interesses leva, às vezes, a consequências que são contrárias às intuições morais comuns, mas isso não é uma razão, segundo Singer, para modificar ou abandonar os princípios morais racionalmente justificados. Se as intuições morais comuns não puderem ser justificadas depois de uma cuidadosa análise, elas devem ser descartadas como a base para os julgamentos morais ${ }^{9}$.

Singer, portanto, não pretende defender a intuição moral comum de que "todos os humanos são iguais". Ele questiona essa concepção na busca de outro princípio moral que possa expandir a comunidade de consideração moral para incluir todos os animais (na medida, é claro, da força dos interesses vivenciados por cada um). Desse modo, parece que o problema que Arneson imputa a Singer é um problema acerca dos pressupostos fundamentais divergentes adotados por cada um deles, e não um problema de coerência interna da filosofia de Singer. 


\section{Bibliografia}

ARNESON, R. J. (1999). What, If Anything, Renders All Humans Morally Equal? In.: JAMIESON, D. Singer and His Critics Philosophers and Their Critics. Oxford-Malden: Brackwell. p.103-128.

BENTHAM, J. (1979). Uma introdução aos princípios da moral e da legislação. 2 ed. Tradução de Luiz João Baraúna. São Paulo: Abril Cultural. (Coleção Os Pensadores).

CARVALHO, M. C. M. (2009). Quem são os membros da comunidade moral? Peter Singer, a senciência e as razões utilitaristas. In.: MORTARI, C. A.; DUTRA, L. H. de A. (orgs.). Anais do $V$ Simpósio Internacional Principia. Florianópolis: NEL/UFSC. p. 343-35

FELIPE, S. T. (2001). Da igualdade. Peter Singer e a defesa ética dos animais contra o especismo. Philosophica, Lisboa, 17/18. p. 21-48.

KUHSE, H. (2003). La ética práctica de Peter Singer. In: SINGER, P. Desacralizar la Vida Humana. Introducción e edición de Helga Kuhse. Traducción de C. G. Trevijano. Madrid: Cátedra. p. 11-27.

SINGER, P. (1999). A response. In: JAMIESON, D. (ed.). Singer and his critics philosophers and their critics. OxfordMalden: Brackwell. p. 269-335.

. (2003a). Los filósofos recuperan su empleo. In:

SINGER, P. Desacralizar la Vida Humana. Introducción e edición de Helga Kuhse. Traducción de C. G. Trevijano. Madrid: Cátedra. p. 75-90.

. (2003b). Matar seres humanos y matar animales. In:

SINGER, P. Desacralizar la Vida Humana. Introducción e edición de Helga Kuhse. Traducción de C. G. Trevijano. Madrid: Cátedra. p. 149-162.

. (2003c). Todos los animales son iguales. In: SINGER, P. Desacralizar la Vida Humana. Introducción e edición de Helga Kuhse. Traducción de C. G. Trevijano. Madrid: Cátedra. p. 107-127.

. (2006). Ética Prática. $3^{\circ}$ ed. Tradução da Second Edition (1993) de J. L. Camargo. São Paulo: Martins Fontes. . (2010). Libertação Animal. Tradução Marly Winckler e Marcelo B. Cipolla. São Paulo: Martins Fontes. 
TELES, M. (2005). Mente Humana e Animal - as perspectivas de Susanne Langer e António Damásio. Philosophica, 25, Lisboa, p. 147-168.

WHITEN, A.; SCHAIK, C. P. van. (2007). The evolution of animal 'cultures' and social intelligence. Philosophical Transactions of The Royal Society B, 362. p. 603-620. Disponível em: http://rstb.royalsocietypublishing.org/content/362/1480/603.full. pdf + html Acesso em 07 dez. 2013.

\section{Notas}

1 Segundo Felipe (2001, p. 34), a "experiência de privação pode-se denominar 'sofrimento'. A capacidade de sofrer distingue os indivíduos que têm interesse, daqueles que, por nada sentirem, não podem ser afectados pela privação em nenhuma de suas variantes".

${ }^{2}$ Ter capacidades mentais superiores é ter consciência de si e do outro, senso de futuro e passado, capacidade de pensamento abstrato, de planejar o futuro, de realizar complexos atos de comunicação, memória mais detalhada, maior conhecimento das suas circunstâncias, em outras palavras, ser racional e autoconsciente. Os indivíduos que são racionais e autoconscientes são considerados pessoas por Singer. É preciso ficar claro que Singer faz uma distinção entre "pessoas" e "seres humanos". "Membro da espécie Homo Sapiens" significa que um indivíduo possui determinada constituição genética que pode ser determinada através de um exame dos seus cromossomos. É nesse sentido que um embrião fecundado a partir de óvulo e esperma humano é considerado um ser humano, bem como aqueles indivíduos que não possuem capacidades mentais superiores, mas possuem a composição genética da espécie. "Pessoa", diferentemente, refere-se ao indivíduo que possui, de fato, capacidades mentais superiores (cf SINGER, 2006, p. 97-98). Existem, segundo Singer, pessoas humanas e pessoas nãohumanas como, por exemplo, os chimpanzés, orangotangos e bonobos entre outros. Existem, também, seres humanos que não são pessoas como, por exemplo, os fetos, recém-nascidos, indivíduos com sérias deficiências nas capacidades mentais superiores, os comatosos, enfim, todos aqueles que não apresentam de fato as capacidades mentais superiores.

${ }^{3}$ Esse é um exemplo imaginário. Não tenho conhecimento suficiente para saber se, de fato, essas duas dores são equiparáveis. Mas para a discussão do exemplo suponhamos que sejam e que a dor de amputar a perna do rato seja, de fato, mais intensa e duradoura do que uma dor de barriga no recémnascido.

${ }^{4} \dot{E}$ importante ressaltar que, nesse primeiro momento, o exemplo acima está comparando o interesse de recém-nascidos com poucos dias de vida, porque, para Singer, eles não possuem quaisquer capacidades mentais superiores 
que possam ser relevantes para os seus interesses. E considera, também, somente crianças órfãs para evitar a complicação dos interesses afetivos dos pais etc.

${ }^{5}$ Singer (2006, p. 71-72, 74, 84, 92ss) faz uma importante distinção na avaliação das circunstâncias relevantes na decisão moral. Existe uma diferença moralmente relevante na aplicação do PICI: a) Em situações, como as que estamos discutindo neste artigo, nas quais nenhuma vida está ameaçada. Nessas situações, o valor da vida de um indivíduo seria irrelevante para a igual consideração de interesses; e b) Em situações nas quais uma vida está ameaçada e seu valor é relevante para a igual consideração de interesses. Neste artigo, estamos discutindo as implicações do PICI unicamente nos casos em que não existem riscos para a vida de nenhum envolvido

${ }^{6}$ Consideramos na análise duas modificações em relação ao exemplo comparativo que discutimos anteriormente, a saber, substituir "recémnascido" por "criança" traz para a discussão as capacidades mentais superiores (racionalidade e autoconsciência). E ao considerar que a criança possui família, os vínculos afetivos que pais e filhos mantêm passam a ser relevantes.

${ }^{7}$ Note-se que o efeito do sofrimento ou da morte de um animal deve ser levado em conta em relação ao seu companheiro ou aos outros membros do seu grupo nos casos em que esses feitos possam vir a ser sentidos pelos outros animais. $O$ que acontece é que, muito provavelmente, os indivíduos que não são pessoas não teriam a capacidade de serem afetado pelo sofrimento do outro. No entanto, isso deve ser decido pelo avanço das pesquisas cientificas sobre essa questão.

${ }^{8}$ Para Carvalho (2009, p 349), "[...] as dores de dente de um ratinho e de uma criança só mereceriam a mesma consideração se, a despeito de serem supostamente de igual intensidade, pudéssemos supor que não haveria nenhuma outra diferença relevante provocada por elas. Todavia, uma vez que por conta das dores de uma criança - como Singer aparentemente entende - um número maior de interesses costuma ser frustrado do que em decorrência das dores de um rato, aquelas devem merecer mais peso, ainda quando sejam tão fortes como as do rato e, muitas vezes também, quando são menos fortes do que elas."

9 "Se nossa teoria moral está apoiada sobre uma base consistente, temos que estar dispostos a aceitar suas implicações se bem que elas nos obriguem a mudar nossos ideais morais sobre questões importantes. Quando se esquece desta exigência, a filosofia moral perde sua capacidade de gerar uma crítica radical dos padrões morais existentes e somente serve para preservar $o$ status quo". (SINGER, 2003a, p. 87; cf. também, SINGER, 1999, p. 295; KUHSE, 2003, p. 18)). 